\title{
AVALIAÇÃO DA PERCEPÇÃO DE RECRUTAS SOBRE DEGRADAÇÃO AMBIENTAL
}

Camila Reis de Santana ${ }^{1}$

Rejane Correa Marques ${ }^{2}$

Resumo: Estudo descritivo, de abordagem quantitativa, que avaliou a percepção de recrutas sobre problemas ambientais e a relação deles com o meio ambiente. A coleta de dados foi realizada a partir de um questionário padronizado. Para 99\% dos participantes é importante conservar o meio ambiente; $47 \%$ considera que a poluição da água é o que mais incomoda; $96 \%$ respondeu que o aquecimento global é real e $77 \%$ que impacta no nosso modo de vida; $27 \%$ creem que os efeitos do aquecimento global afetam ou já afetaram sua vida e $38 \%$ que isto não influencia suas decisões diárias. As percepções dos participantes do estudo são importantes para orientar as ações e práticas sustentáveis a serem realizadas no ambiente militar. Sugere-se que escolas de recrutas trabalhem ações ambientais, pois estas podem influenciar de maneira benéfica as suas atitudes ambientais.

Palavras-chave: Meio Ambiente; Sustentabilidade; Jovens; Militar

Abstract: The aims of this descriptive study with a quantitative approach were to measure the perception of young recruits about environmental problems and the relationship of these recruits with the environment. To gather the data we used a standardized questionnaire with open and closed questions. 99\% of participants considered that conserving the environment was important; $47 \%$ $47 \%$ consider that water pollution is the most concerning; $96 \%$ responded that global warming is real, and $77 \%$ that it impacts our quality of life; $27 \%$ believe that the effects of global warming affect or have already affected their lives and $38 \%$ that this does not influence their daily decisions. The perceptions of the study participants are important to guide sustainable actions and practices to be carried out in the military environment. It is suggested that recruit schools should address environmental issues.

Keywords: Environment; Sustainability; Young; Military.

\footnotetext{
${ }^{1}$ Universidade Federal do Rio de Janeiro, Macaé - RJ. E-mail: camilak889@gmail.com Link para o Lattes: http://lattes.cnpq.br/2799887253453620 ;

2 Universidade Federal do Rio de Janeiro, Macaé - RJ. E-mail: rejanecmarques@globo.com Link para o Lattes: http://lattes.cnpq.br/9981984419027348 .
} 


\section{Introdução}

Os elevados padrões de consumo, as pressões populacionais e 0 desenvolvimento industrial contribuem para a degradação ambiental, que cada vez mais surge como uma preocupação global e crescente. A complexidade dos desafios ambientais e a sua globalização sugere a introdução de políticas mais ambiciosas, capazes de enfrentar os principais problemas ambientais e promover o desenvolvimento sustentável, cujo conceito deve ser uma preocupação e uma responsabilidade de todos.

Os problemas ambientais de hoje podem ser organizados em cinco grandes desafios, quais sejam: (1) fornecer alimentos, água e energia de maneira sustentável; (2) reduzir as mudanças climáticas e adaptar-se aos seus impactos; (3) projetar um futuro sem poluição e desperdício; (4) criar cidades eficientes, saudáveis e resilientes; e (5) promover decisões e ações informadas (NASEM, 2019). Esses grandes desafios estão alinhados às questões apresentadas e discutidas nos Objetivos de Desenvolvimento Sustentável (ODS) das Nações Unidas. Os ODS buscam transformar nosso mundo, aumentando a igualdade ambiental e social através de inovação sustentável e multidisciplinar (UN, 2015).

A incorporação de responsabilidade ambiental, econômica e social requer equipes multi e interdisciplinares com diversas competências. Profissionais que não apenas possuam uma grande profundidade de conhecimento em seu campo, mas também amplas experiências em outros campos, prosperarão melhor nesse cenário interdisciplinar. Para criar um mundo mais sustentável e empenhado em questões relacionadas com sustentabilidade, conforme descrito nos ODS, os indivíduos devem ser portadores de conhecimento, habilidades, valores e atitudes que os capacitam a contribuir para o desenvolvimento sustentável (WALLEN et al., 2019).

A principal tarefa das Forças Armadas de um país é defender e proteger sua soberania e interesses. O setor de defesa - marinha, exército, aeronáutica - é caracterizado por sua complexidade, com seu numeroso pessoal e muitas instalações com inúmeros produtos e serviços. Devido à natureza de suas missões e atividades, o setor de defesa tem um papel social importante e também possui um grande potencial de prejudicar ou beneficiar o meio ambiente de maneira altamente visível. Comparado a outros domínios governamentais, os serviços de defesa têm, potencialmente, um impacto ambiental mais significativo do que outras instituições (MAGAGULA, 2019; MYHRE et al., 2013; SMIT; VAN DER MERWE, 2018) .

O papel da gestão ambiental no setor militar é uma questão recente e complexa. O setor de defesa supervisiona um número importante de operações e atividades específicas e bem estabelecidas, que são realizadas pelos diferentes ramos, ou seja, a marinha, o exército e a aeronáutica e todo o seu setor administrativo. A principal tarefa das forças armadas de um país é defender e proteger sua soberania e interesses. Para cumprir essas responsabilidades, os setores militares devem ter armas, treinar seus membros e ter acesso a extensas áreas de treinamento com características naturais para

Revbea, São Paulo, v.16, № 1: 393-409, 2021. 
combate. Portanto, atividades para equipar e treinar as forças armadas terão impactos ambientais como qualquer outra atividade humana (RAMOS; MELO, 2005; SMIT; VAN DER MERWE, 2018; WALLEN et al., 2019).

O impacto das atividades do setor militar se estende aos problemas ambientais mais importantes nos níveis global, regional e local, incluindo gases de efeito estufa, depleção da camada de ozônio, ruído, efluentes de águas residuais, poluição do ar, resíduos perigosos e contaminação do solo (RAMOS; MELO, 2005). As forças armadas conduzem uma ampla gama de atividades e, de várias maneiras, representam uma seção transversal da sociedade. Embora grande parte dessa atividade seja especificamente militar, como treinamento de armas e tráfego aéreo militar, muitas dessas atividades têm contrapartes claras na sociedade civil (RAMOS; MELO, 2005; SMIT; VAN DER MERWE, 2018; MAGAGULA, 2019).

A Organização do Tratado do Atlântico Norte (OTAN) destaca que é responsabilidade de todo cidadão contribuir para 0 desenvolvimento sustentável e os elementos pertencentes ao setor de defesa não são exceção (NATO, 1996). O setor militar deve cumprir as políticas e leis ambientais estabelecidas para o resto da sociedade, exceto em circunstâncias extremas, nas quais sua missão de defender a nação e manter sua soberania possa estar em risco. Além disso, ao atuar de maneira ambientalmente responsável, o setor militar é capaz de exercer influência positiva significativa na sociedade. O exército, por exemplo, não é apenas responsável pelo gerenciamento de grandes áreas de terra, mas também opera instalações industriais, desempenha funções de serviço público, é um importante comprador público e envolve e treina um grande número de pessoas sob uma liderança unificada. Como tal, é uma importante instituição social. Também possui um grande potencial de prejudicar ou beneficiar o meio ambiente de maneira altamente visível.

Para promover o vínculo entre o setor militar e o meio ambiente, precisamos aumentar nossas pesquisas sobre métodos de desenvolvimento, medição e promoção da integração de práticas ambientais, nos diferentes níveis das organizações militares, nos processos de tomada de decisão, logística e operação, em particular. Isso pode ser conseguido integrando o ambiente em todo o processo de gerenciamento das organizações militares, em vez de mantê-lo como um aspecto isolado (MAGAGULA, 2019; MYHRE et al., 2013).

Rodrigues et al. (2012) destacam que as discussões sobre o meio ambiente foram e são precursoras de Políticas Públicas e ações ambientais propostas e/ou executadas pelos governos mundiais. Há inúmeros mecanismos que contribuem para uma leitura geopolítica aproximando-se de uma realidade local e dos problemas sociais que envolvem sociedade e meio ambiente.

Nesse contexto, a percepção dos recrutas, ou seja, de jovens engajados em um ambiente militar sobre os problemas ambientais, se torna um importante 
aliado para o poder público quanto à leitura de uma realidade social, configurando-se como meio de apoio aos instrumentos e ferramentas para futuras ações voltadas à Educação Ambiental, desenvolvendo interfaces e permitindo as interações propostas na execução de tarefas. As forças armadas modernas realizam amplas atividades militares, usam grandes áreas para fins de treinamento e operações militares e são confrontadas com um foco global no comportamento ambientalmente responsável. Essas condições obrigam os militares a garantir que os soldados demonstrem a atitude correta em relação a comportamentos e conhecimentos sobre os diversos ambientes físicos, sociais e culturais que ocupam e sobre os quais exercem efeitos (SMIT; VAN DER MERWE, 2018).

O termo "alfabetização ambiental" vem sendo utilizado desde o final da década de 1960 e é um conceito complexo por natureza, que abrange numerosos e diversos componentes significativos (MILLER; SPOOLMAN, 2012). É um termo usado quando se refere a três elementos geralmente reconhecidos da alfabetização ambiental, a saber, atitude, comportamento e conhecimento do ambiente - de acordo com o amplo consenso terminológico da literatura (WRIGHT, 2008; SMIT; VAN DER MERWE, 2018). Pode incluir crenças relacionados a opiniões sobre percepções e valores sociais relacionados ao meio ambiente.

A orientação conceitual sobre a compreensão dos diferentes componentes da alfabetização ambiental foi descrita por vários pesquisadores (ALP et al., 2008; ÖZDEN, 2008; MEINHOLD; MALKUS, 2005; LOPEZ et al., 2007; SMIT; VAN DER MERWE, 2018). Apesar da falta de uma definição precisa da alfabetização ambiental como conceito, uma definição de Roth (1992) amplamente aceita foi adotada pela maioria dos pesquisadores da área. Roth definiu alfabetização ambiental como conhecimento e atitude de um indivíduo sobre o meio ambiente e questões ambientais, habilidades e motivação para trabalhar na resolução de problemas ambientais e envolvimento ativo no trabalho para manter o equilíbrio dinâmico entre a qualidade de vida e a qualidade do meio ambiente. $O$ autor sugeriu um modelo útil que postula três níveis diferentes em um continuum de alfabetização ambiental crescente:

- O primeiro nível é a alfabetização ambiental nominal, o que implica um entendimento básico dos processos ambientais e um desenvolvimento da conscientização e sensibilidade em relação às questões ambientais.

- No nível seguinte, alfabetização ambiental funcional, a compreensão e o conhecimento da natureza e das interações entre seres humanos e sistemas naturais são registrados.

- O terceiro nível, rotulado como alfabetização ambiental operacional, engloba aqueles que foram além da alfabetização funcional, avaliam rotineiramente ações e tomam medidas para melhorar ou manter um ambiente saudável.

Este modelo postula, portanto, uma progressão pelos níveis de alfabetização ambiental em estágios que incluem consciência de baixo nível, através da preocupação e compreensão de possíveis ações no alto nível. A 
alfabetização não se desenvolve necessariamente através um processo linear. Portanto, a ação pode, por exemplo, preceder a compreensão (ROTH, 1992).

Considerando os fundamentos e a aplicabilidade da percepção, há várias mensurações e contextos existentes em diversas raízes epistemológicas com inter-relações entre elas. Historicamente, os estudos da percepção humana tiveram início no século XIX quando Wilhelm Wundt, então considerado o pai da psicologia, consagrou o primeiro laboratório experimental com estudos aplicados na temática de percepções (SIMÕES; TIEDEMANN, 1985). A partir daí, estudos nessa área nortearam movimentos, teorias, escolas e em meados dos anos 60 as análises de percepção deram início às discussões também no tocante ao meio ambiente.

Holtzer (1993) lembra que alguns autores humanistas como Roger Downs, Kevin Lynch, Willian Kirk, Lukermann, Hugh Prince e Leonard Guelk, desenvolveram suas abordagens teóricas sobre percepção ambiental com distintas percepções de valores. Os estudos sobre percepção ambiental evoluíram ampliando as iniciativas de aplicação deste conceito como, por exemplo, a elaboração do Projeto 13 - desenvolvido em 1973 pela UNESCO sobre "Percepção de Qualidade Ambiental" com enfoque na importância da pesquisa em percepção ambiental para planejamento do meio ambiente.

A percepção é intrínseca ao ser humano, e este reage diversamente às relações interpessoais e sobre o meio (FAGGIONATO, 2009). Então, por qual motivo indivíduos de um mesmo grupo social expressam atitudes e pensamentos distintos? Para autores como Simões e Tiedemann (1985), Ribeiro (2003), Melazo (2005); Rodrigues et al. (2012), a resposta está nos valores presentes nas manifestações resultantes das percepções como cultura, classe social, história de vida. São esses fatores que influenciam diretamente no processo.

O caminho importante e inerente às mudanças ambientais é aprimorar nosso conhecimento por meio da educação e mudar a atitude e o comportamento de cada indivíduo. Isso permite que todas as pessoas possuam conhecimento ambiental abundante, atitude ambiental adequada e comportamento ambiental correto. O objetivo final da Educação Ambiental é melhorar o comportamento ambiental das pessoas. Portanto, é necessário e urgente cultivar a alfabetização ambiental das pessoas, corrigir a atitude ambiental, os cuidados ambientais e ecológicos, e o cumprimento dos comportamentos ambientais.

Por isso é fundamental discutir a temática ambiental entre os recrutas, a fim de que eles se empoderem desse conhecimento e consigam identificar problemas relacionados à questão ambiental, conhecendo e replicando ações resolutivas e preventivas, agregado à comunidade, procurando amenizar os riscos ambientais a que todos estão expostos. Através desse estudo pretendemos identificar nos recrutas o grau de conhecimento e de sensibilização sobre os problemas ambientais com vistas ao fortalecimento e valorização da importância da conservação do ecossistema marinho. 


\section{Material e Métodos}

Trata-se de um estudo descritivo, de abordagem quantitativa. $O$ estudo foi realizado no Núcleo de Formação de Reservistas Navais - NFRN, unidade gerida pela Base Aérea Naval de São Pedro da Aldeia (BAeNSPA), pertencente ao Complexo Aeronaval de São Pedro da Aldeia/RJ, Marinha do Brasil.

A casuística contou com 94 voluntários do sexo masculino, com idades entre 18 e 19 anos, escolaridade de nível médio, recrutados pelo NFRV/ BAeNSPA. Esses recrutas recebem formação com duração entre 4 e 5 meses para cada turma. Uma turma a cada semestre, formando até 100 recrutas por ano que após cerimônia de juramento à Bandeira tornam-se MarinheirosRecrutas. Foram incluídos todos os alunos recrutas do NFRV/BAeNSPA que concordaram em participar do estudo, sendo o recrutamento em si o critério de inclusão. Foram excluídos os recrutas que se recusaram a participar do projeto, ou aqueles que por algum motivo, durante a pesquisa, foram desligados da escola do NFRV/BAeNSPA.

\section{Coleta de dados}

Inicialmente houve uma visita ao Núcleo de Formação de Reservistas Navais para apresentação do projeto e posteriormente foram agendadas visitas para a aplicação dos questionários.

A coleta de dados foi realizada a partir de um questionário padronizado que serviu para identificação socioeconômica e continha perguntas com respostas abertas e fechadas relacionadas a assuntos pertinentes ao meio ambiente. A caracterização socioeconômica, incluiu informações sobre estado civil, grau de escolaridade, profissão, número de filhos e renda familiar. A segunda parte do questionário incluiu 16 perguntas que serviram para a captação da percepção ambiental dos participantes, concentrando informações sobre a importância de conservar o meio ambiente, aquecimento global e o que mais o incomodava o indivíduo, do ponto de vista da degradação ambiental. As perguntas relativas a essa segunda parte do questionário são apresentadas na Tabela 2 e Gráficos 1 a 4 . O questionário foi entregue aos participantes, havendo padronização de tempo de até 1 hora para respostas, sem interferência externa.

\section{Análise dos dados}

Os dados foram organizados em planilhas Microsoft $\AA$ Excell 2011. Para análise das variáveis quantitativas foram calculados as médias e os desviospadrão, os valores mínimos, máximos e medianos. As variáveis categóricas são descritas por meio de suas frequências absolutas (n) e relativas (\%).

\section{Aspectos Éticos}

O trabalho seguiu os preceitos da bioética, respeitando a Resolução 466/2012 (CONSELHO NACIONAL DE SAÚDE, 2012). O protocolo de pesquisa foi submetido à apreciação do Comitê de Ética em Pesquisa 
Envolvendo Seres Humanos da Universidade Federal do Rio de Janeiro Campus Macaé (CEP UFRJ-Macaé) e teve aprovação por meio do parecer $n$. CAAE: 15355319.0.0000.5699. A anuência dos participantes da pesquisa foi livre de vícios (simulação, fraude ou erro), dependência, subordinação ou intimidação, após explicação completa e pormenorizada sobre a natureza da pesquisa, seus objetivos, métodos, benefícios previstos, potenciais riscos e o incômodo que esta possa acarretar, todos os participantes assinaram o Termo de Consentimento Livre e Esclarecido, autorizando sua participação voluntária na pesquisa.

\section{Resultados}

Dos 100 jovens recrutados no Núcleo de Formação de Reservista, 94 aceitaram participar do estudo. Esses recrutas, todos do sexo masculino e com idades entre 18 e 19 anos, receberam formação com duração entre 4 e 5 meses. Na Tabela 1 são apresentados os dados socioeconômicos dos participantes do estudo.

Tabela 1: Variáveis socioeconômicas dos participantes do estudo. N=94

\begin{tabular}{|c|c|c|c|c|c|}
\hline Variáveis & Média & DP & Mediana (Min-Max) & $\mathbf{N}$ & $\%$ \\
\hline Idade & 18,74 & 0,6 & $19(18-21)$ & & \\
\hline Renda $(\mathrm{R} \$)$ & 2967,28 & 2450,21 & $2500(765-19000)$ & & \\
\hline \multicolumn{6}{|l|}{ Escolaridade } \\
\hline ensino médio & & & & 72 & 77 \\
\hline ensino médio incompleto & & & & 10 & 11 \\
\hline Superior incompleto & & & & 3 & 3 \\
\hline Não informado & & & & 9 & 9 \\
\hline \multicolumn{6}{|l|}{ Local de Residência } \\
\hline Rio de Janeiro & & & & 75 & 80 \\
\hline Espirito Santo & & & & 18 & 19 \\
\hline Não informado & & & & 1 & 1 \\
\hline \multicolumn{6}{|l|}{ Cor/raça } \\
\hline Branco & & & & 31 & 33 \\
\hline Preto & & & & 22 & 23,4 \\
\hline Pardo & & & & 40 & 42,6 \\
\hline Não informado & & & & 1 & 1 \\
\hline \multicolumn{6}{|l|}{ Estado Civil } \\
\hline Solteiro & & & & 92 & 98 \\
\hline Casado & & & & 1 & 1 \\
\hline Não informado & & & & 1 & 1 \\
\hline \multicolumn{6}{|l|}{ Filhos } \\
\hline Sim & & & & 1 & 1 \\
\hline Não & & & & 93 & 99 \\
\hline
\end{tabular}

Fonte: Autoras (2020) 
A idade média dos participantes foi de 18,74 anos $(D P=0,60)$ e a renda familiar de $\mathrm{R} \$ 2967,27$ ( $\mathrm{DP}=2450,21)$. A maioria tem o ensino médio completo (77\%), são solteiros (98\%), sem filhos (99\%), residentes no estado do Rio de Janeiro $(80 \%)$ e se identificam como pardos $(42,6 \%)$.

A aplicação dos questionários nos permitiu verificar como esses jovens percebem questões diretamente ligadas à conservação do meio ambiente. $A$ Tabela 2 (próxima página) apresenta as respostas (sim/não) dadas as perguntas sobre a importância da conservação ambiental e conhecimento sobre mudanças climáticas.

Os resultados mostram que $99 \%$ dos participantes consideram importante conservar o meio ambiente, mas ao serem questionados do "por que você considera importante conservar o meio ambiente", $71 \%$ respondeu que era "por ter valor em si mesmo e por ser importante na preservação das espécies", 18\% "por ser útil para os seres humanos" e 2\% não respondeu.

Entre os participantes da pesquisa, $47 \%$ não soube informar se no município em que reside há áreas de preservação ambiental e $62 \%$ não costuma visitar esse tipo de lugar. Quando perguntados sobre qual o grau de conhecimento que tem sobre áreas de preservação ambiental, $79 \%$ respondeu que tem pouco conhecimento e $20 \%$ nenhum conhecimento sobre o assunto.

Tabela 2.Conhecimento sobre a importância da conservação dos recursos naturais

\begin{tabular}{|c|c|c|c|c|c|c|}
\hline \multirow[t]{2}{*}{ Perguntas } & \multicolumn{2}{|c|}{ Sim } & \multicolumn{2}{|c|}{ Não } & \multicolumn{2}{|c|}{$\begin{array}{l}\text { Não sabe/ } \\
\text { respondeu }\end{array}$} \\
\hline & $n$ & $\%$ & $n$ & $\%$ & $N$ & $\%$ \\
\hline $\begin{array}{l}\text { 1. Você considera importante conservar o meio } \\
\text { ambiente? }\end{array}$ & 93 & 99 & 1 & 1 & 0 & 0 \\
\hline $\begin{array}{l}\text { 4. Você saberia dizer se no município onde você reside } \\
\text { há alguma área de preservação ambiental? }\end{array}$ & 49 & 52 & 44 & 47 & 1 & 1 \\
\hline 5. Você costuma visitar áreas de preservação? & 35 & 37 & 58 & 62 & 1 & 1 \\
\hline $\begin{array}{l}\text { 6. Você acredita que os efeitos do aquecimento global } \\
\text { modificarão o seu modo de viver num futuro próximo? }\end{array}$ & 77 & 82 & 17 & 18 & 0 & 0 \\
\hline $\begin{array}{l}\text { 7. Você acredita que os efeitos do aquecimento global } \\
\text { modificarão o modo de viver da sociedade como um } \\
\text { todo? }\end{array}$ & 76 & 81 & 18 & 19 & 0 & 0 \\
\hline $\begin{array}{l}\text { 10. Você considera importante conhecer melhor o mar, } \\
\text { principalmente como fonte de alimentos e fonte de } \\
\text { recursos biológicos e minerais? }\end{array}$ & 90 & 96 & 4 & 4 & 0 & 0 \\
\hline 14. Você conhece as diretrizes do Protocolo de Quioto? & 8 & 9 & 86 & 91 & 0 & 0 \\
\hline $\begin{array}{l}\text { 15. Você acredita que o aquecimento global seja algo } \\
\text { real? }\end{array}$ & 90 & 96 & 4 & 4 & 0 & 0 \\
\hline $\begin{array}{l}\text { 16. Os efeitos do aquecimento global afetam ou já } \\
\text { afetaram sua vida de alguma forma? }\end{array}$ & 25 & 27 & 68 & 72 & 1 & 1 \\
\hline
\end{tabular}

Fonte: Autoras (2020)

Sobre aquecimento global, $96 \%$ acredita que seja algo real, $82 \%$ que os efeitos do aquecimento global mudarão seu modo de viver num futuro Revbea, São Paulo, v.16, № 1: 393-409, 2021. 
próximo e $81 \%$ crê que esses efeitos modificarão o modo de viver de toda a sociedade. Porém, apenas $27 \%$ respondeu que os efeitos do aquecimento global afetam ou já afetaram sua vida de alguma forma. Ao serem perguntados sobre a importância do aquecimento global para eles mesmos, $68 \%$ respondeu que era muito importante, $26 \%$ importante, $3 \%$ pouco importante e $3 \%$ não respondeu. Vale ressaltar que apenas $9 \%$ afirmou que conhece as diretrizes do Protocolo de Quioto. Quando perguntados se o tema aquecimento global influencia suas decisões, 38\% respondeu que não (Gráfico 1).

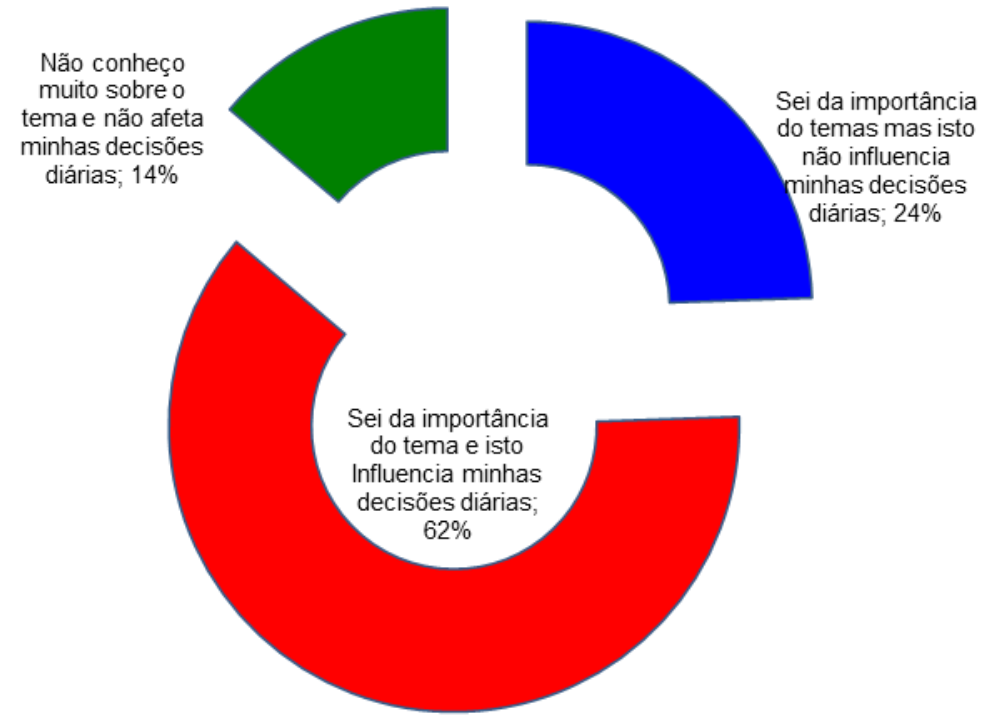

Gráfico 1: Percentual de respostas sobre como o aquecimento global influencia as decisões diárias dos participantes da pesquisa. $\mathrm{N}=94$. Fonte: Autoras (2020)

Quanto ao tema degradação ambiental, $47 \%$ dos participantes respondeu que a poluição da água era o que mais incomodava, seguido das mudanças climáticas com 27\% (Gráfico 2).

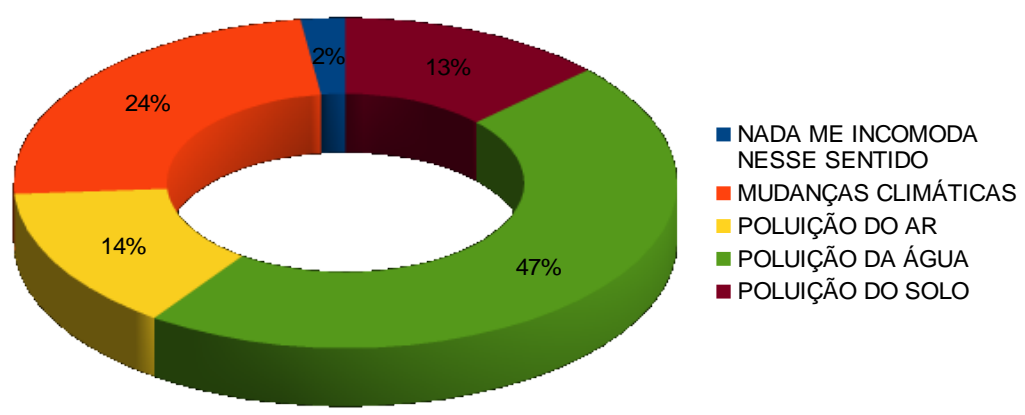

Gráfico 2: Percentual de respostas sobre o que mais incomoda do ponto de vista da degradação ambiental. Fonte: Autoras (2020) 
Perguntados se é importante conhecer o mar como fonte de alimentos, de recursos biológicos e minerais, 96\% respondeu que sim (Tabela 2). Ao questionarmos os recrutas sobre a Amazônia Azul, 54\% respondeu que o termo se referia ao território marítimo brasileiro e $19 \%$ nunca ouviu falar sobre o assunto (Gráfico 3).

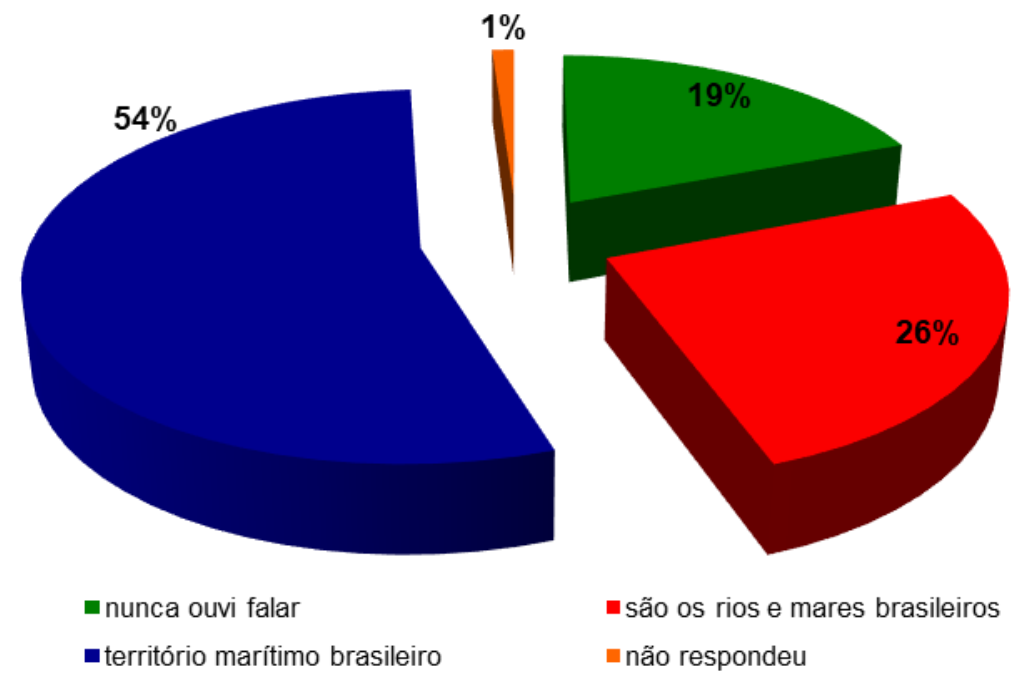

Gráfico 3: Percentual de respostas sobre o que significa Amazônia Azul. N=94

Fonte: Autoras (2020)

Também perguntamos em quais situações você considera o mar, os rios e seus afluentes como sendo mais importantes para o ser humano, sendo que $73 \%$ respondeu que o mar é igualmente importante como fonte de alimento, lazer, meio de transporte e fonte de energia (Gráfico 4).

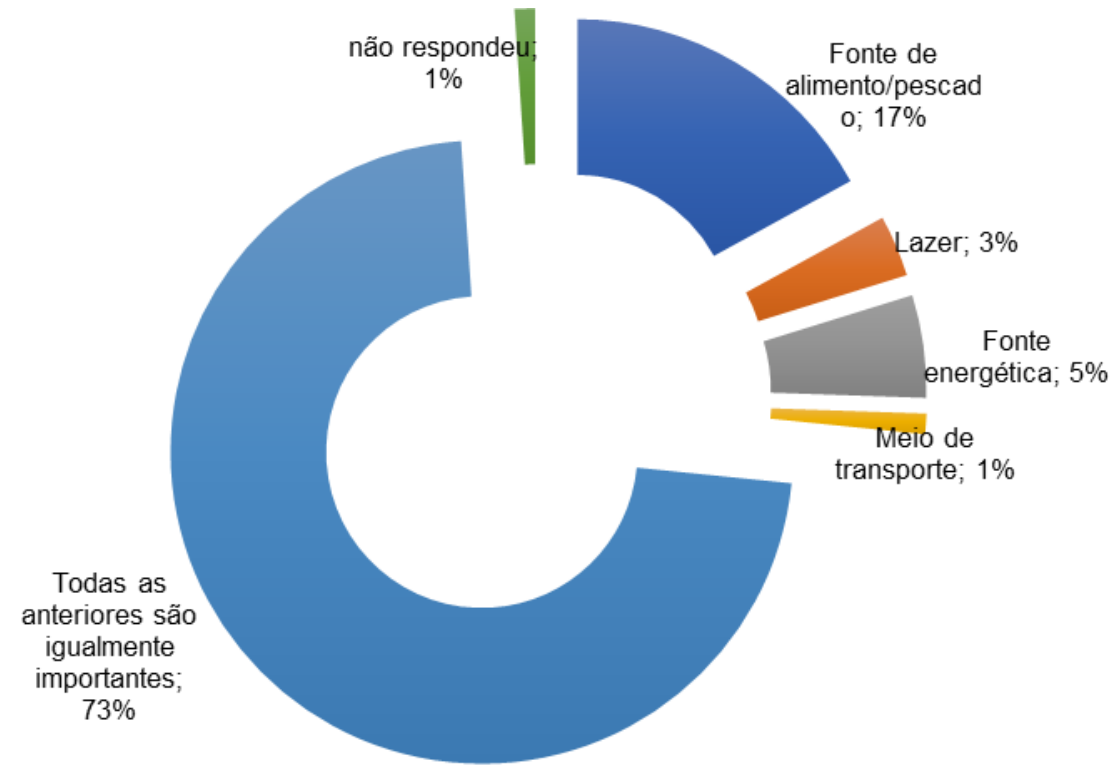




\section{Discussão}

Apesar de $80 \%$ da população brasileira viver próximo ao litoral, falta a ela uma maior consciencialização da importância dos oceanos. A conservação marinha envolve processos complexos e de lenta implementação. Castro et al. (2017) diz que o desenvolvimento da mentalidade marinha na nossa sociedade, principalmente nos ensinos fundamental e médio, permitirá a gradual mudança de posturas frente à Amazônia Azul. Isto é importante, pois essa área abriga um bioma único, indivisível e frágil, tanto diante da contaminação ambiental quanto das mudanças climáticas globais previstas para as próximas décadas.

Nesse sentido consideramos apresentar no presente estudo um apontamento do que os jovens recrutas compreendem e a sensibilização desses, para com os problemas ambientais, com vistas às futuras ações educativas. Tendo em vista que ainda existe uma lacuna que gera grandes oportunidades de melhoria na relação poder público/academia/sociedade civil no tocante à Educação Ambiental, é fundamental analisar os dados desse estudo, coletados das questões interpretativas, assim como direcionar a promoção de ações educativas voltadas para escolas de recrutas, moradores do entorno e sociedade em geral, disseminando o conhecimento sobre biodiversidade e conservação ambiental e os impactos da degradação ambiental na saúde humana, de forma a fortalecer e a valorizar a importância da conservação de todo o ecossistema.

Entre os participantes, 99\% consideram importante conservar o meio ambiente. Como o estudo trata apenas da identificação do nível de conhecimento dos recrutas, não avaliaremos como se deu ou se dá a Educação Ambiental desses jovens, ou quais as correntes de pensamento da EA que os orientaram durante toda sua vida. Para Lucie Sauvé (2005) há quinze correntes de pensamentos e atuação da EA; são elas: Naturalista, Conservacionista/Recursista, Resolutiva, Sistêmica, Científica, Humanista, Moral/Ética, Holística, Biorregionalista, Práxica, Crítica Social, Feminista/Ecofeministas, Etnográfica, Ecoeducação, Para a sustentabilidade. Nosso estudo volta-se para uma abordagem tendenciando para a Sustentabilidade com o conceito e condição absorvidos pela EA na "promoção do desenvolvimento socioeconômico da humanidade, em condição indissociável da conservação dos recursos naturais, na equidade de sua utilização para estas e as futuras gerações" (SAUVÉ, 2005).

Nenhum dos recrutas considera os oceanos como fonte de lazer ou o meio de transporte importante para os seres humanos, ainda que a maioria resida em regiões litorâneas, onde o turismo movimenta a economia regional. Sabe-se que "em aproximadamente $8.500 \mathrm{~km}$ de faixa litorânea, concentram-se $80 \%$ da população, são produzidos $90 \%$ do produto interno bruto (PIB) brasileiro e estão localizados os principais destinos turísticos nacionais" (MARINHA DO BRASIL, 2020). 
Quando questionados sobre Amazônia Azul, 54\% dos recrutas responderam que o termo se referia ao território marítimo brasileiro dentro do conceito que trazemos, $19 \%$ nunca ouviu falar sobre o assunto, enquanto $24 \%$ entende que se trata dos rios e dos mares brasileiros. Imprescindível conhecermos nossos mares e suas riquezas, o impacto no meio ambiente e nas nossas vidas para que possamos saber o que queremos conservar, o que estamos valorizando ou desvalorizando, quem os está protegendo ou não e de que forma isso se dá.

A percepção de que o mar é igualmente importante como fonte de alimento, lazer, meio de transporte e fonte de energia se deu para $73 \%$ dos participantes, quando perguntados sobre a importância do mar para os seres humanos. Quando se pensa em Economia Azul como a economia do desenvolvimento que vem dos mares, a conservação ambiental é a nossa principal aliada. Deste modo, $47 \%$ dos participantes respondeu ser a poluição da água o que mais incomoda e $96 \%$ considera importante conhecer melhor o mar, principalmente como fonte de alimentos e fonte de recursos biológicos e minerais. De fato, acreditamos na importância em conhecermos melhor o mar como fonte de recursos e de relevância socioeconômica, vinculando a essas questões e a tantas outras que envolvem preservação de espécies e conservação da natureza, para ampliarmos nossa visão sobre a importância de conservá-lo.

Com uma exceção, todos os participantes concordaram ser importante conservar o meio ambiente. As respostas dadas sobre a importância da conservação dos recursos naturais correspondem aos chamados "valores de manutenção da vida" (VAN RIPER; KYLE, 2014). A maioria dos recrutas reconhece a importância dos serviços ecossistêmicos prestados pelo ambiente e indica um alto nível de preocupação e conhecimento ambiental. Acoplado a essa categoria está o reconhecimento da biodiversidade, que se traduz em uma preocupação biocêntrica e não apenas em uma visão de mundo antropocêntrica, a saber, preocupações de "diversidade biológica".

O reconhecimento do valor intrínseco da natureza é capturado nas respostas que advogam a proteção e preservação de toda a vida e habitats, e a conservação da natureza. O reconhecimento desse valor intrínseco da natureza, em vez de uma linha de raciocínio mais utilitária (MILLER; SPOOLMAN, 2012) significa um bom nível de sensibilidade ambiental e um nível bem desenvolvido de preocupação ambiental entre um grupo significativo de recrutas. Essa preocupação vai além do mero valor utilitário atribuído pelos participantes e indica progressão ao longo de um continuum crescente de alfabetização ambiental postulada por Roth (1992). O reconhecimento do imperativo organizacional de cuidar do meio ambiente não aparece na literatura geral sobre alfabetização ambiental, mas é inerente ao dever do soldado. Esse tipo de resposta é atribuível à influência das normas, especificamente às subjetivas ou à sensação de que "outras pessoas significativas" esperam um certo padrão de comportamento (GIFFORD; NILSSON, 2014). 
Um considerável número de respostas avaliou questões relacionadas ao aquecimento global como sem importância para a sua vida, o que implica que os recrutas não precisam se preocupar com o meio ambiente, pois pode não ser um imperativo organizacional. Esse equívoco potencialmente prejudicial deve ser observado pelos líderes militares e deve ser abordado pela educação e treinamento em meio ambiente militar.

Poucos recrutas responderam que não é importante cuidar ou conhecer melhor o meio ambiente. Embora essa seja uma opinião mantida por uma minoria, é essencial que o serviço militar tome nota e dissipe essa ilusão, porque legal e eticamente essa atitude pode gerar controvérsia. São necessários apenas alguns soldados que desconhecem a importância da conduta ambientalmente responsável, para o Estado se envolver em processos caros, ou pior, comprometer a execução da missão devido ao comportamento insensível ao meio ambiente dos soldados. Um exemplo é a poluição da água em países com escassez de água (MOSHER et al., 2008). O lócus de controle externo indica uma incapacidade de se apropriar do comportamento ambiental.

Em relação às respostas positivas apresentadas na Tabela 2 muitas respostas implicam que uma parte importante dos participantes do estudo não entendeu a pergunta ou não conseguiu assinalar uma resposta legítima. Um exemplo é que $96 \%$ respondeu que o aquecimento global é real, $77 \%$ que impacta no nosso modo de vida, mas apenas $27 \%$ respondeu que os efeitos do aquecimento global afetam ou já afetaram sua vida de alguma forma e $38 \%$ que isto não influencia suas decisões diárias.

Nenhuma explicação para isso é imediata. Mas uma possível explicação é que alguns recrutas entenderam mal a questão enquanto estavam sob a falsa impressão de que a entenderam. Talvez eles acreditassem que boas práticas ambientais podem melhorar o sucesso da missão, mas não podiam explicar suas crenças. Outra explicação é que os participantes tentaram responder à pergunta de acordo com o que pensavam ser a resposta "correta", com base nas expectativas percebidas pela pesquisadora. Matthies et al. (2012, p. 278) chamam esse comportamento de "norma subjetiva" e a definem como as "expectativas percebidas de outras pessoas significativas". Nesse caso, o outro significativo foi a pesquisadora, que pode ter sido considerada de "classificação mais alta". Contudo, isso é discutível, porque esse efeito não aparece em nenhuma das outras respostas às perguntas, algo que se esperaria se existissem percepções de respostas "boas" entre os participantes. No entanto, essa questão exige uma avaliação mais aprofundada.

Quando questionados de que forma imagina o que terá de transformação em sua vida com os efeitos do aquecimento global, $25,53 \%$ dos participantes não quiseram ou não souberam responder, enquanto nas perguntas abertas, 6,38\% não ofereceu nenhuma resposta. Essa taxa de não resposta merece comentários. Kelly et al. (2003) e Negev et al. (2010) sustentaram que as perguntas abertas são mais exigentes para os 
respondentes e que, por isso, são prováveis de ter taxas de não resposta. Isso é especialmente verdadeiro para os participantes menos motivados ou fatigados pela pesquisa. Negev et al. (2010), por exemplo, registraram uma taxa de não resposta de $40 \%$ em uma pesquisa de problemas, causas e soluções ambientais. Portanto, a taxa de não resposta no presente estudo não é inaceitavelmente alta.

Pode-se concluir que programas de educação e treinamento ambiental podem influenciar de maneira benéfica às atitudes ambientais dos recrutas. Nesse sentido a Educação Ambiental entra como forte aliada. No início do século XX, a sociedade começava a refletir sobre o ambiente e Freud divulgava que a civilização é a culpada por nossa miséria, com a crença de que seríamos mais felizes se retrocedêssemos as condições primitivas apresentando-nos três origens do sofrimento humano: a prepotência da natureza, a fragilidade de nosso corpo e a insuficiência das normas que regulam a sociedade. Já que nunca dominaremos completamente a natureza, e nosso organismo faz parte dela, sempre será uma construção transitória, limitada em adequação e desempenho (FREUD, 2011).

Os militares do mundo todo estão sob crescente pressão para conduzir suas operações de maneira ambientalmente responsável. Essa é a maneira ética e moralmente apropriada de agir, e um imperativo legal. As missões militares podem ser comprometidas por conduta ambiental inadequada e as consequências de práticas ambientais militares ruins podem permanecer por muito tempo após a resolução de conflitos ou intervenções. Soldados com um grau adequado de conhecimento ambiental podem impedir que isso aconteça. Para Smit e Van der Merwe (2018), soldados com atitude ambiental adequada, conhecimento adequado e padrões de comportamento que lhes permitam operar efetivamente em qualquer ambiente em que devem executar sua missão, não queimam livros religiosos, não destroem artefatos culturais importantes, não ignoram tabus culturais, nem violam leis ambientais ou prejudicam o ambiente físico em que eles operam. Eles também não tolerarão práticas ambientais insustentáveis que possam ter um efeito adverso em sua própria saúde e segurança, bem como na população civil onde operam.

\section{Conclusões}

Pode-se afirmar, que programas de educação e treinamento ambiental podem influenciar de maneira benéfica às atitudes ambientais dos recrutas. Desse modo, as percepções dos participantes do estudo são importantes para orientar as ações e práticas sustentáveis a serem realizadas no ambiente militar. Sugere-se que escola de recrutas trabalhe ações ambientais. Entre as ações que podem ser incorporadas está o oferecimento de uma disciplina de Educação Ambiental, de modo a estimular o desenvolvimento de atitudes e valores relacionados ao meio ambiente e a sociedade em que integra. Palestras, oficinas e rodas de conversa sobre o assunto são outra alternativa para os recrutas compreenderem que também são responsáveis pela 
conservação ambiental e que a degradação do ambiente implica em consequências negativas para toda a sociedade.

\section{Agradecimentos}

Ao Núcleo de Formação de Reservista da Base Aérea Naval de São Pedro da Aldeia por permitirem a realização do estudo nas suas dependências. A Universidade Federal do Rio de Janeiro, por tornar possível o mestrado de CRS.

\section{Referências}

ALP, E. A survey on Turkish elementary school students' environmental friendly behaviours and associated variables. Environmental Education Research, v. 14, n. 2, p. 129-143, 2008. DOI: https://doi.org/10.1080/13504620802051747

MARINHA DO BRASIL. Economia Azul. Acessado em: 27 de maio de 2020. Disponível em: https://www.marinha.mil.br/economia-azul/sobre

CASTRO, B.M. et al. A Amazônia Azul: recursos e preservação. Revista USP, n. 113, p. 7-26, 6 jun. 2017.

FAGGIONATO, S. Percepção ambiental. Material de Apoio - Textos, 2009. Disponível em: < http://educar.sc.usp.br/biologia/textos/m_a_txt4.html>.

FREUD, S. O mal-estar na civilização. Tradução de Paulo César de Souza. São Paulo: Penguin Classics. Companhia de das Letras, 2011.

GIFFORD, R. The dragons of inaction: Psychological barriers that limit climate change mitigation and adaptation. American Psychologist, v.66, n. 4, p. 290302, 2011.

GIFFORD, R.; NILSSON, A. Personal and social factors that influence prenvironmental concern and behaviour: A review. International Journal of Psychology, v. 49, p.141-157, 2014.

LOPEZ, A. et al. Texas Latino college students' attitudes toward natural resources and the environment. Journal of Wildlife Management, v. 71, n. 4, p. 1275-1280, 2007.

MAGAGULA, H.B. Military integrated environmental management programme of the South African National Defence Force. South African Geographical Journal, v. 102, n. 2, p. 170-189, 2019.

MATTHIES, E., SELGE, S.; KLÖCKNER, C.A. The role of parental behaviour for the development of behaviour specific environmental norms-the example of recycling and re-use behaviour. Journal of Environmental Psychology, v. 72, p. 277-284, 2012.

MEINHOLD, J.L.; MALKUS, A.J. "Adolescent environmental behaviours: Can knowledge, attitudes and self-efficacy make a difference?" Environment and Behaviour, v. 37, n. 4, p. 511-532, 2005. 
MELLAZO, G. C. A percepção ambiental e Educação Ambiental: uma reflexão sobre as relações interpessoais e ambientais no espaço urbano. Olhares \& Trilhas, Uberlândia, v. 6, n. 1, p. 45-51, 2005.

MILLER, G.T.; SPOOLMAN, S.E. Living in the environment. $19^{\text {th }}$ ed, Boston: Cengage Learning, 2018.

MOSHER, D.E. et al. Green warriors: Army environmental considerations for contingency operations from planning through post-conflict. Santa Monica: Rand Corporation. 2008.

NATIONAL ACADEMIES OF SCIENCES, ENGINEERING, AND MEDICINE NASEM. Environmental Engineering for the 21st Century: Addressing Grand Challenges. Washington, DC: The National Academies Press, 2019..

NORTH ATLANTIC TREATY ORGANISATION - NATO. Environmental Guidelines for the Military Sector: A Joint Sweden-United States Project. North Atlantic Treaty Organisation, Committee on the Challenges of Modern Society. 1996.

ÖZDEN, M. Environmental awareness and attitudes of student teachers: An empirical research. IRGEE, v. 17, n.1, p. 40-55, 2008.

RAMOS, T.B., MELO, J.J. Environmental management practices in the defence sector: assessment of the Portuguese military's environmental profile. Journal of Cleaner Production, v. 13, n. 12, p. 1117-1130, 2005.

RIBEIRO, L. M. O papel das representações sociais na Educação Ambiental. 2003. Dissertação (Mestrado em Educação) - Pontifícia Universidade Católica, Rio de Janeiro, 2003.

RODRIGUES, M. L. et al. A percepção ambiental como instrumento de apoio na gestão e na formulação de políticas públicas ambientais. Saude soc., São Paulo, v. 21, supl. 3, p. 96-110, Dec. 2012.

ROTH, CE. Environmental literacy: Its roots, evolution, and directions in the 1990s. Columbus, OH: 1992. https://files.eric.ed.gov/fulltext/ED348235.pdf

SAUVÉ, L. Uma cartografia das correntes em Educação Ambiental. In: SATO, M.; CARVALHO, I.C.M. (Orgs.) Educação Ambiental. Porto Alegre: Artmed, 2005, p.17-44.

SIMÕES, E. A. Q.; TIEDEMANN, K. B. Psicologia da percepção. São Paulo: EPU, v. 10, n. 2, 1985.

SMIT, H. A. P. \& VAN DER MERWE, J. H. Military environmental literacy in the South African army. Scientia Militaria: South African Journal of Military Studies, v. 46, n.1, p. 59-77, 2018. DOI: 10.5787/46-1-1225

UNITED NATIONS - UN. Transforming our world: the 2030 Agenda for Sustainable Development, A/RES/70/1, 2015. http://www.un.org/ga/search/view doc.asp?symbol=A/ RES/70/1\&Lang=E 
VAN RIPER, C. J.; KYLE, G.T. Capturing multiple values of ecosystem services shaped by environmental world views: A spatial analysis. Journal of Environmental Management, v. 145, p.374-384, 2014.

WALLEN, B. M. et al. Long-term Impact on Environmental Attitudes and Knowledge Assessed over Three Semesters of an Environmental Engineering Sequence. American Society for Engineering Education, 2019. https://www.asee.org/public/conferences/140/papers/26444/view

WRIGHT, J.M. Web-based versus in-class: An exploration of how instructional methods influence postsecondary students' environmental literacy. The Journal of Environmental Education, v. 39, n. 2., p.33-45, 2008. 